\title{
Feasibility of Along-Track Displacement Measurement From Sentinel-1 Interferometric Wide-Swath Mode
}

\author{
Hyung-Sup Jung, Member, IEEE, Zhong Lu, Senior Member, IEEE, and Lei Zhang, Member, IEEE
}

\begin{abstract}
The European Space Agency's Sentinel-1, a C-band imaging radar mission to be launched in mid-2013, will provide a continuity of radar data for monitoring the changing Earth. The azimuth resolution of Sentinel-1's background mode, interferometric wide-swath (IW) mode, is four times lower than that of European remote-sensing satellite (ERS) and Envisat systems. Therefore, the measurement accuracy of along-track displacement from Sentinel-1 IW images presumably will be significantly reduced. In this paper, we test the feasibility of along-track displacement measurement from Sentinel-1 IW mode. We simulate Sentinel-1 IW synthetic aperture radar (SAR) images from the ERS raw data that captured the coseismic deformation of the 1999 Hector Mine earthquake in California. Along-track displacement maps are generated using multiple-aperture interferometric SAR (MAI) and intensity tracking techniques, respectively, and are compared with GPS measurements. The root-mean-square (rms) error between the synthetic Sentinel-1 MAI and GPS measurements is about $9.6 \mathrm{~cm}$, which corresponds to only $0.5 \%$ of the azimuth resolution. The rms error between the along-track displacements from synthetic Sentinel-1 offset tracking and GPS is about $27.5 \mathrm{~cm}$, which is about $1.4 \%$ of the azimuth resolution. These results suggest that the MAI method will still be useful to measure along-track displacements from Sentinel-1 IW InSAR imagery and that it would be difficult to effectively measure the along-track displacements by the Sentinel-1 offset tracking method.
\end{abstract}

Index Terms-European Remote Sensing (ERS), interferometric synthetic aperture radar (InSAR), multiple-aperture InSAR (MAI), Sentinel-1, synthetic aperture radar (SAR).

\section{INTRODUCTION}

$\mathbf{S}$ ENTINEL-1, the next generation of C-band radar missions from the European Space Agency (ESA), is due to launch in mid-2013. Sentinel-1 will extend European Remote Sensing (ERS) and Envisat radar legends to provide a continuity of radar imagery to the user community. Sentinel-1 has four different operational modes: 1) strip map mode; 2) interferometric wide

Manuscript received November 3, 2011; revised March 3, 2012; accepted April 25, 2012. Date of publication June 8, 2012; date of current version December 19, 2012. This work was supported in part by U.S. Geological Survey Volcano Hazards Program and in part by Space Core Technology Development Program through the National Research Foundation of Korea funded by the Ministry of Education, Science and Technology (2011-0020884).

H.-S. Jung is with the Department of Geoinformatics, The University of Seoul, Seoul 130-743, Korea (e-mail: hsjung@uos.ac.kr).

Z. Lu is with the Cascades Volcano Observatory, U.S. Geological Survey, Vancouver, WA 98683 USA (e-mail: lu@ usgs.gov).

L. Zhang is with the Department of Land Surveying and Geo-Informatics, The Hong Kong Polytechnic University, Kowloon, Hong Kong (e-mail: zhanglen@gmail.com).

Color versions of one or more of the figures in this paper are available online at http://ieeexplore.ieee.org.

Digital Object Identifier 10.1109/TGRS.2012.2197861 swath (IW) mode; 3) extra-wide-swath mode; and 4) wave mode [1]. Sentinel-1's revisit time of 12 days is shorter than that of ERS and Envisat, which will enhance interferometric synthetic aperture radar (InSAR) coherence in general [2]. A constellation of two Sentinel-1 satellites will provide a revisit of six days. The background mode of Sentinel-1 operation is the IW mode, which provides a wide coverage of $250 \mathrm{~km}$ with medium resolutions of 5 and $20 \mathrm{~m}$ in range and azimuth directions, respectively [2], [3].

The ground range resolution of the Sentinel-1 IW mode is improved by about five times over those of the ERS and Envisat systems by using large chirp bandwidth, while the azimuth resolution is four times lower than those of the ERS-1/-2 and advanced synthetic aperture radar (image mode) systems to provide a wide coverage of $250 \mathrm{~km} \mathrm{[2],} \mathrm{[3].} \mathrm{Since} \mathrm{lower}$ azimuth resolution of Sentinel-1 IW can be compensated by higher ground range resolution, the coherence of Sentinel-1 IW interferograms would be similar to that of ERS and Envisat interferograms if a similar number of multilooks is used in InSAR processing [2]. That is, the accuracy of InSAR line-of-sight (LOS) surface deformation measurement from Sentinel-1 IW is expected to be similar to that of ERS and Envisat. However, the measurement accuracy of the along-track displacement for Sentinel-1 IW will likely be much lower than that for ERS and Envisat, because its azimuth resolution is four times lower than that of ERS and Envisat. Therefore, the accuracy of along-track displacement measured from Sentinel-1 images will likely be significantly reduced.

It is well known that source geometry in deformation modeling is ambiguous if it is estimated from vertical deformation data alone [4]. Direct measurements of the deformation field in three dimensions allow for better resolution of the parameters of deformation models for volcanic activity, earthquakes, and other processes, including the geometry of the deformation source. InSAR is a powerful technique for mapping surface deformation, but it is limited to the measurement of ground surface deformation along the radar LOS direction. Because ERS, Envisat, and Sentinel-1 satellites have near-polar orbits (i.e., approximately north-south ground tracks) and right-looking imaging geometry, it is impossible to determine 3-D surface deformation from LOS InSAR data alone, even when multiple independent interferograms with different viewing angles are used jointly [5]. The bottleneck is in resolving the along-track displacement.

Two techniques have been realized to map the along-track displacement: One is the pixel tracking technique [6]-[8], and 
the other is the multiple-aperture InSAR (MAI) [9], [10]. Pixel offset tracking is achieved through cross correlation of SAR images and is limited by the azimuth pixel resolution. Previous studies have demonstrated that the accuracy of along-track displacement from the pixel offset method on ERS data with high coherence is limited to $12-15 \mathrm{~cm}$ [11]-[13]. This accuracy corresponds to about $2.4 \%-3.0 \%$ of the azimuth resolution. The accuracy of along-track displacement from the offset method on advanced land observation satellite phased array type L-band synthetic aperture radar (ALOS PALSAR) images can reach to $1.6 \%$ of the azimuth resolution [14]. Assuming that the SAR sensor onboard Sentinel-1 is as good as the ALOS PALSAR, the achievable accuracy of the along-track displacement from the offset tracking technique would be less than about $32 \mathrm{~cm}$ (1.6\% of $20 \mathrm{~m}$ of the azimuth resolution) [14]. This accuracy is not good enough to measure the along-track displacements from most earthquakes and volcanic activity.

Recently developed MAI technique [9], [10] represents a remarkable improvement in measuring along-track displacement over the pixel offset tracking method. The accuracy of this method depends on the coherence as well as the effective azimuth antenna dimension which is approximately equal to twice the azimuth resolution. The achieved accuracies of the MAI method for ERS and ALOS data are about 6.3 and $3.6 \mathrm{~cm}$, respectively [9], [15]. These respectively correspond to about $1.3 \%$ and $0.8 \%$ of the azimuth resolution, which are significantly better than the results from the pixel offset tracking method. Assuming that the Sentinel-1 SAR can achieve this accuracy, MAI technique can produce along-track displacement with an accuracy of $16 \mathrm{~cm}$, which is twice as good as the offset tracking method.

In this paper, we simulate synthetic Sentinel-1 SAR images from the ERS raw data spanning the 1999 Hector Mine earthquake and assess the achievable accuracy of the alongtrack displacement by Sentinel-1 MAI and intensity tracking measurements, both of which will be compared with GPS data. We hope that this study will provide guidance in determining the feasibility of the along-track displacement measurement from Sentinel-1 IW imagery.

\section{Data Set And Processing}

A feasibility study on the along-track displacement measurement from the Sentinel-1 is carried out by using ERS-2 raw data pair (descending track 127 and frame 2907) acquired on September 15 and October 20, 1999. The image covers the epicenter of the Hector Mine earthquake, California $\left(M_{w}\right.$ of 7.1), which occurred on October 16, 1999. This coseismic ERS InSAR pair is ideal to test the feasibility of the Sentinel-1 alongtrack displacement measurement in that the following holds: 1) Interferometric coherence is high; 2) large displacement exists; and 3) in situ measurement is available to test the measurement accuracy of along-track displacements.

The Sentinel-1 IW mode is implemented as a Terrain Operation with Progressive Scans in order to image a wide swath width of $250 \mathrm{~km}$ with $100 \%$ burst synchronization optimized for InSAR processing [16], [17]. The effective Doppler bandwidth of this instrument is about $380 \mathrm{~Hz}$, and its chirp band-
TABLE I

SYSTEM PARAMETERS OF SENTINEL-1 IW AND ERS

\begin{tabular}{lcc}
\hline \multicolumn{1}{c}{ Parameters } & Sentitel-1 IW & ERS \\
\hline Effective Azimuth Antenna Dimension (m) & 40 & 10 \\
Effective Doppler Bandwidth (Hz) & 380 & 1420 \\
Satellite Velocity (m/s) & 7600 & 7100 \\
Chirp Bandwidth (MHz) & 56.5 & 15.6 \\
Carrier Frequency (GHz) & 5.405 & 5.300 \\
Mean incidence angle (deg) & 33 & 23 \\
Azimuth Resolution (m) & 20 & 5 \\
Ground Range Resolution (m) & 5 & 25 \\
\hline
\end{tabular}

width is $56.5 \mathrm{MHz}$, while the effective Doppler and chirp bandwidths of ERS-1/-2 are about $1460 \mathrm{~Hz}$ and $15.6 \mathrm{MHz}$, respectively [2], [3]. The large chirp bandwidth improves the range resolution with respect to ERS-1/-2 systems, while the small effective Doppler bandwidth reduces the azimuth resolution. Consequently, the azimuth and range resolutions of Sentinel-1 IW imagery are about $20 \mathrm{~m}$ in azimuth and $5 \mathrm{~m}$ in range, respectively. Table I summarizes the system parameters of Sentinel-1 IW and ERS-1/-2 [2], [3].

Synthetic Sentinel-1 IW single look complex (SLC) images are simulated using the ERS-2 InSAR pair to test the feasibility of along-track displacement measurements. For this simulation, the processed Doppler bandwidth of $380 \mathrm{~Hz}$ is applied to ERS-2 raw data, and then, a complex average of five azimuth pixels is carried out. This simulation is not perfect because high ground range resolution of the Sentinel-1 IW data $(5 \mathrm{~m})$ cannot be simulated from ERS-2 data $(25 \mathrm{~m})$. However, it is adequate to test the feasibility of along-track displacement measurements because the accuracy of along-track displacement largely depends on the azimuth pixel size and the processed Doppler bandwidth [10]. We produce four along-track displacement maps from both ERS-2 and synthetic Sentinel-1 IW InSAR pairs using both the MAI and the offset tracking methods, respectively.

For the MAI processing of the ERS-2 and the synthetic Sentinel-1 InSAR pairs, the average Doppler centroid is calculated from the Doppler centroids of master and slave data. The forward and backward Doppler centroids are determined from the effective Doppler bandwidth and a normalized squint of 0.5. Then, the subaperture Doppler bandwidth is determined from the Doppler parameters calculated. The same average Doppler centroid of $62.3 \mathrm{~Hz}$ is used for both the ERS-2 and the Sentinel-1 processing. However, the forward and backward Doppler centroids and subaperture Doppler bandwidth for the ERS-2 (i.e., 417.6, -293.0 , and $652.8 \mathrm{~Hz}$, respectively) are different from those for the Sentinel-1 (i.e., 252.3, -127.7, and $190.0 \mathrm{~Hz}$, respectively) because the effective Doppler bandwidths of the ERS-2 and the Sentinel-1 are 1420 and $380 \mathrm{~Hz}$, respectively (see Table I). These Doppler parameters are used for azimuth common band processing [10]. In the master and slave data, forward- and backward-looking SLC images are created, and a complex average of five azimuth pixels is additionally applied to the forward- and backward-looking SLC images to simulate the synthetic Sentinel-1 IW images. The characteristics of the MAI pairs are summarized in Table II. The generated forward- and backward-looking SLC images of 
TABLE II

Characteristics of Interferometric Pairs Used in This STUdy

\begin{tabular}{|c|c|c|c|c|c|c|c|}
\hline Pairs & $\begin{array}{l}\text { Acquisition } \\
\text { Date }\end{array}$ & $\begin{array}{l}f_{D C, f}^{\mathrm{b}} \\
(\mathrm{Hz})\end{array}$ & $\begin{array}{r}f_{D C, c}{ }^{\mathrm{b}} \\
(\mathrm{Hz})\end{array}$ & $\begin{array}{c}f_{D C, b}^{\mathrm{b}} \\
(\mathrm{Hz})\end{array}$ & $\begin{array}{l}\Delta f_{D, S}{ }^{\mathrm{c}} \\
(\mathrm{Hz})\end{array}$ & $\begin{array}{l}B_{\perp}{ }^{\mathrm{d}} \\
(\mathrm{m})\end{array}$ & $\begin{array}{l}\Delta B_{\perp}{ }^{\mathrm{d}} \\
(\mathrm{m})\end{array}$ \\
\hline ERS-2 & $\begin{array}{c}15 / 09 / 1999^{\mathrm{a}} \\
20 / 10 / 1999\end{array}$ & 417.6 & 62.3 & -293.0 & 652.8 & -17 & -0.007 \\
\hline $\begin{array}{l}\text { Synthetic } \\
\text { Sentinel-1 }\end{array}$ & $\begin{array}{c}15 / 09 / 1999^{\mathrm{a}} \\
20 / 10 / 1999\end{array}$ & 252.3 & 62.3 & -127.7 & 190.0 & -17 & -0.007 \\
\hline
\end{tabular}

${ }^{a}$ Master image; ${ }^{b}$ Forward, average, and backward Doppler centroids; ${ }^{c}$ Sub-aperture processing

bandwidth; ${ }^{d}$ the perpendicular baseline of the forward-looking interferogram and the perpendicular baseline difference.

the master and slave data have the same azimuth and range positions without explicit coregistration because the processing algorithm proposed by Jung et al. [10] is used. Multilooked forward- and backward-looking differential interferograms are created and smoothed using a Goldstein filter [18] with a window size of 32 to improve interferometric coherence. The final MAI interferograms are corrected from the residual flatEarth and topographic phases through the method by Jung et al. [10]. The MAI interferometric phase $\left(\phi_{\mathrm{MAI}}\right)$ is converted into along-track displacement $(x)$ using the following equation:

$$
x=-\frac{l}{4 \pi n} \phi_{\mathrm{MAI}}
$$

where $l$ is the effective antenna length and $n$ is a normalized squint that is a fraction of the full aperture width [9], [10]. The effective antenna lengths of the ERS-2 and the Sentinel-1 are 10 and $40 \mathrm{~m}$, respectively (see Table I).

We generate the along-track displacement using the intensity tracking technique - the widely used method on image offset estimates [7]. This intensity tracking method can be performed to remarkable accuracy when the coherence is retained because the speckle patterns of the two images are correlated [7]. It should be noted that the fringe visibility technique [7] can also be used for image offset estimates for InSAR pairs with excellent coherence. At each pixel location, we use multiple patch sizes varying from $64 \times 64$ to $128 \times 128$ single-look pixels with a step size of 16 pixels in both azimuth and range directions. Therefore, a total of 25 offset measurements are carried out at a position. The final offset measurement is calculated by averaging the 25 offset measurements after removing outliers. The along-track displacement is then calculated from the azimuth offset $\left(O_{\mathrm{az}}\right)$ as given by

$$
x=O_{\mathrm{az}} \cdot \Delta_{\mathrm{az}}
$$

where $\Delta_{\mathrm{az}}$ is the azimuth pixel size.

\section{RESULTS}

\section{A. Theoretical Analysis}

A theoretical standard deviation of the along-track displacement measurement from MAI is shown in Fig. 1. It is calculated from (1) as given by

$$
\sigma_{x}=\frac{l}{4 \pi \cdot n} \sigma_{\phi, \mathrm{MAI}}
$$

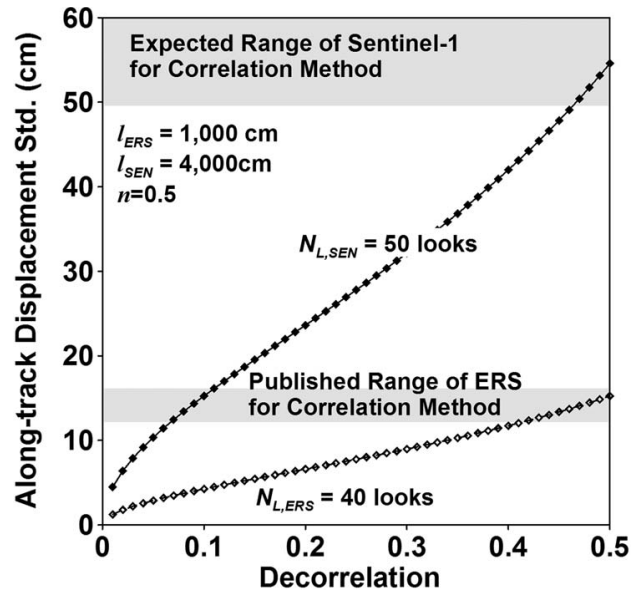

Fig. 1. Variation of theoretical standard deviation of along-track displacement for ERS and Sentinel-1 with respect to decorrelation. Values of $l_{\mathrm{ERS}}=$ $1000 \mathrm{~cm}$ and $l_{\mathrm{SEN}}=4000 \mathrm{~cm}, n=0.5$, and $N_{L, \mathrm{ERS}}=40$ and $N_{L, \mathrm{SEN}}=$ 50 are used to calculate the standard deviation, where $l$ is the effective antenna length, $n$ is a normalized squint, $N_{L}$ is the effective number of looks, and subscripts of ERS and SEN denote ERS and Sentinel-1 SAR systems, respectively. The gray shaded areas present the published range of cross correlation method for ERS in [4]-[6] and the expected range for Sentinel-1, respectively.

where $\sigma_{x}$ and $\sigma_{\phi, \text { MAI }}$ are the standard deviations of the displacement measurements and the MAI phases, respectively [9]. The $\sigma_{\phi, \mathrm{MAI}}$ is defined by

$$
\sigma_{\phi, \mathrm{MAI}} \approx \frac{1}{\sqrt{N_{L}}} \frac{\sqrt{1-\gamma^{2}}}{\gamma}
$$

where $\gamma$ is the total correlation [19] and $N_{L}$ is the effective number of looks for forward- or backward-looking interferograms. Note that the standard deviation of MAI interferometric phase would be at least twice as large as that of interferometric phase obtained from full aperture processing because a normalized squint $(n)$ of 0.5 is generally used for MAI processing and the azimuth resolution degrades with aperture loss. Using (3) and (4), the theoretical standard deviation of the alongtrack displacement measurements is calculated based on the processing parameters in Table I. Moreover, the improvement of the standard deviation of the phase by Goldstein filtering [18] is also considered [10]. As shown in Fig. 1, the standard deviation of the along-track displacement rapidly increases as the total decorrelation increases. When the correlations are $0.95,0.8$ and 0.5 , the standard deviations of the along-track 


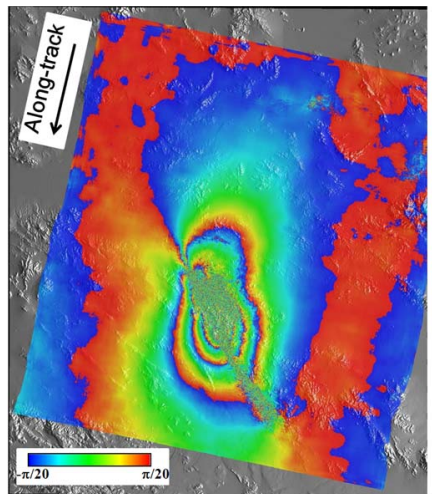

(a)

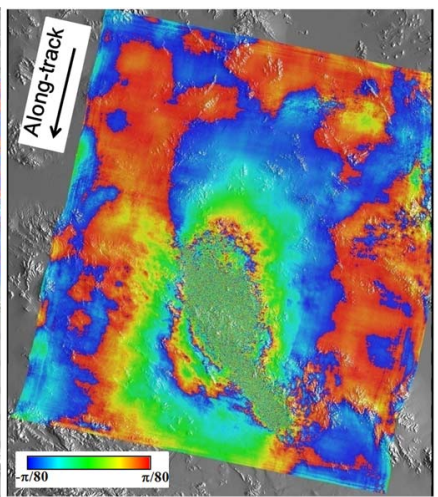

(b)
Fig. 2. MAI interferograms for (a) ERS and (b) synthetic Sentinel-1. Note that the fringes of the interferograms are presented between $-\pi / 20$ and $\pi / 20$ for ERS and $-\pi / 80$ and $\pi / 80$ for Sentinel-1. These ranges correspond to -25 to $25 \mathrm{~cm}$.

displacement are approximately 3,7 , and $15 \mathrm{~cm}$, respectively, for ERS and about 10, 24, and $55 \mathrm{~cm}$, respectively, for Sentinel-1. These results indicate that the performance of the MAI method largely depends on the coherence of the MAI image. In order to reach the accuracy of along-track displacement of ERS MAI, the Sentinel-1 MAI image should have higher coherence than the ERS one. The published standard deviations of the cross correlation method for the ERS system range from 13 to $15 \mathrm{~cm} \mathrm{[11]-[13],} \mathrm{and} \mathrm{the} \mathrm{expected} \mathrm{standard}$ deviation for the Sentinel-1 falls between 52 and $60 \mathrm{~cm}$ (Fig. 1). Therefore, the MAI performance of Sentinel-1 for $N_{L}=50$ is much better than the offset tracking method and that accuracy of less than $15 \mathrm{~cm}$ can be achieved in high-coherence region $(\gamma \geq 0.9)$ using the MAI method. Moreover, the accuracy of Sentinel-1 MAI measurement can be more precise than that of ERS offset measurement if the interferometric coherence is high $(\gamma \geq 0.9)$. Therefore, the MAI method should be suitable for mapping the effective along-track displacement measurement from earthquakes and volcanoes using Sentinel-1 IW SAR imagery.

\section{B. Simulation Analysis}

The ERS and synthetic Sentinel-1 MAI interferograms are shown in Fig. 2. One fringe in the interferograms represents between $-\pi / 20$ and $\pi / 20$ for ERS and $-\pi / 80$ and $\pi / 80$ for Sentinel-1, both of which correspond to an along-track displacement ranging from -25 to $25 \mathrm{~cm}$. For the generation of the MAI interferograms, the forward- and backward-looking SLC images are generated using a normalized squint of $n=0.5$ and effective antenna lengths of $l=10$ and $40 \mathrm{~m}$ for ERS and Sentinel-1, respectively, and the final MAI interferograms are formed by the complex-conjugate operation of the forward-and backward-looking differential interferograms using the corresponding parameters of the interferometric pairs summarized in Table II. The MAI interferograms from ERS and Sentinel-1 show similar along-track displacement patterns. However, the ERS MAI interferogram is much more coherent than the Sentinel-1 IW MAI because the azimuth angular beam width

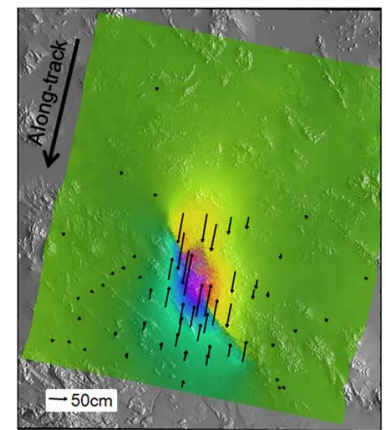

(a)

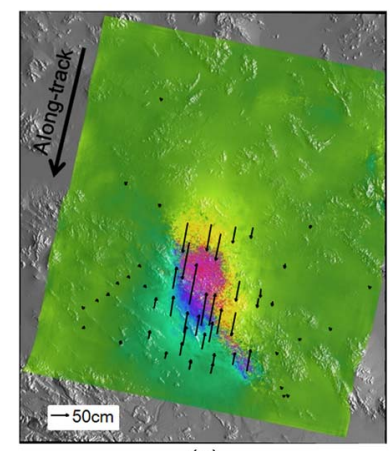

(c)

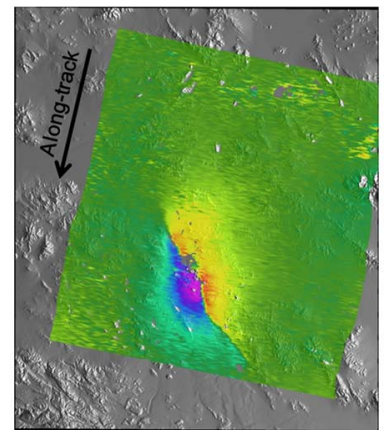

(b)

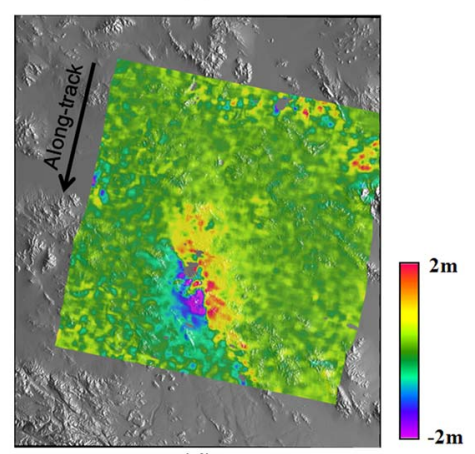

(d)
Fig. 3. Along-track displacement maps measured from (a) MAI and (b) offset methods for ERS InSAR pair and (c) MAI and (d) offset methods for synthetic Sentinel-1 InSAR pair.

of ERS MAI is four times larger than that of Sentinel-1 MAI. The noncoherent areas of the MAI interferograms shown in Fig. 2 are caused by large surface disturbance. In conventional SAR interferometry, this generally occurs when the displacement difference between adjacent pixels is more than the radar wavelength or when the imaged areas are significantly disturbed. Although the MAI interferogram is not related to the radar wavelength but the effective azimuth antenna length, a MAI interferogram is affected by large surface displacement because a MAI interferogram depends on the coherence of the corresponding LOS interferogram [10]. The azimuth resolution for Sentinel-1 is four times as poor as that for ERS-2. The reduction in azimuth resolution degrades the coherence of LOS interferograms of Sentinel-1 over areas with large deformation gradients. Consequently, the noncoherent area of the Sentinel-1 MAI interferogram is larger than that of ERS-2.

Fig. 3 shows along-track displacement maps measured from MAI and pixel offset methods for ERS and Sentinel-1 IW images. The black arrows in Fig. 3(a) and (c) represent the GPS observations from [20], which are projected to the alongtrack direction. The GPS observations distributed in areas with coherence higher than 0.7 are used to assess the accuracy of along-track displacement measurements from the MAI and pixel offset methods. The along-track displacement maps in Fig. 3(a) and (c) are respectively generated from MAI interferograms in Fig. 2(a) and (b) using (1), while those in Fig. 3(b) and (d) are respectively created from the azimuth offset fields of ERS and synthetic Sentinel-1 InSAR pairs using (2). All of the along-track displacement maps shown in Fig. 3 represent a similar pattern, but their noise levels are 


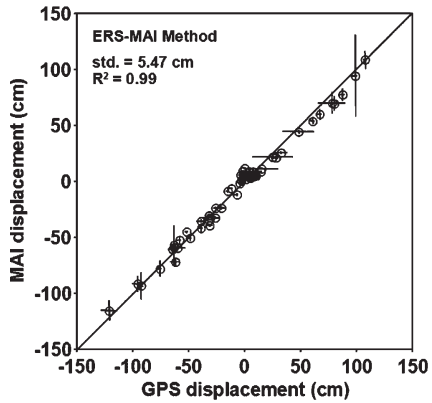

(a)

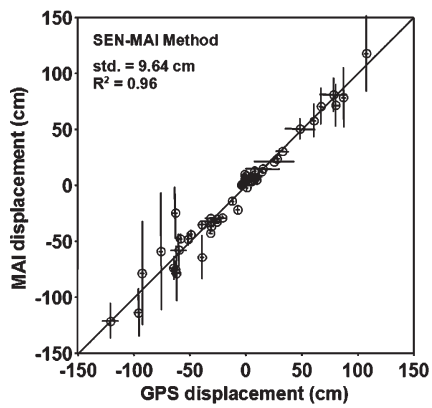

(c)

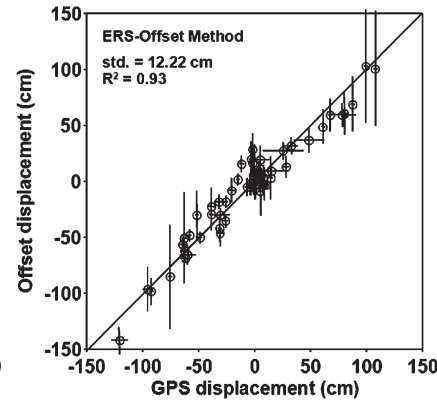

(b)

(d)

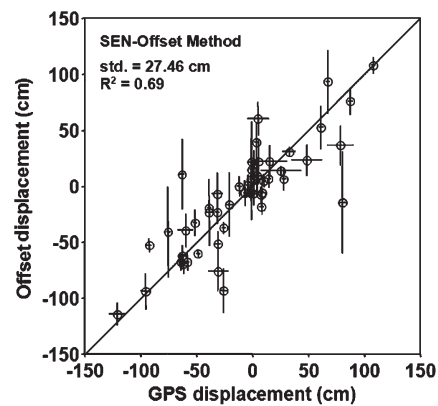

Fig. 4. Comparison of MAI and offset displacements with GPS displacements. (a) and (b) are MAI (std. $\left.=5.47 \mathrm{~cm} ; R^{2}=0.99\right)$ and offset (std. = $\left.12.22 \mathrm{~cm} ; R^{2}=0.93\right)$ displacements of ERS, respectively, and (c) and (d) are MAI (std. $\left.=9.64 \mathrm{~cm} ; R^{2}=0.96\right)$ and offset $\left(\right.$ std. $=27.46 \mathrm{~cm} ; R^{2}=0.69$ ) displacements of synthetic Sentinel-1, respectively. Offset measurements from GPS are plotted in horizontal axis, while offset measurements from SAR are plotted in vertical axis. Circles and bars denote GPS and MAI or offset displacements with error bars at a $95 \%$ confidence level.

different. The MAI measurements [Fig. 3(a) and (c)] are better than the offset ones [Fig. 3(b) and (d)]. Moreover, the alongtrack displacement measurements from ERS [Fig. 3(a) and (b)] are superior to those corresponding ones from the synthetic Sentinel-1 [Fig. 3(c) and (d)] due to the difference in azimuth resolution between ERS and Sentinel-1.

Fig. 4 shows the comparison of the along-track displacements measured from MAI and offset methods with the GPS displacements shown in Fig. 3(a) and (c). The root-meansquare (rms) error between ERS MAI and GPS displacements is about $5.5 \mathrm{~cm}$, corresponding to only $1.1 \%$ of the azimuth resolution of the ERS SAR system [Fig. 4(a)]. This result is slightly better than the rms error (about $6.3 \mathrm{~cm}$ ) published by Bechor and Zebker [9], because the method proposed in [10] improves the coherence of the MAI interferogram by the following: 1) azimuth common band filtering; 2) multilooking and phase filtering; and 3) efficient corrections of the flat-Earth and topographic phases. However, both results are worse than the accuracy achieved by ALOS PALSAR MAI measurement ( $0.8 \%$ of the azimuth resolution) [15] due to the low phase noise of ALOS PALSAR data. The rms error between ERS offsets and GPS displacements [Fig. 4(b)] is about $12.2 \mathrm{~cm}$, corresponding to $2.4 \%$ of the azimuth resolution. This result is in agreement with the accuracy of $12-15 \mathrm{~cm}$ published previously [11]-[13], but worse than the offset result of $1.6 \%$ achieved from the ALOS PALSAR [14]. The accuracy of ERS offset displacements is twice as low as that of the ERS MAI ones. The determinant of correlation $\left(r^{2}\right)$ from the offset tracking method is 0.93 , while it is 0.99 for MAI. These results further confirm that along-track displacement measurement from MAI is superior to the offset tracking method [15].

Fig. 4(c) compares the synthetic Sentinel-1 MAI measurements with GPS displacements. The rms error and the determinant of correlation are about $9.6 \mathrm{~cm}$ and 0.96 , respectively. The accuracy of $9.6 \mathrm{~cm}$ corresponds to only $0.5 \%$ of the azimuth resolution. This result is about twice as poor as ERS MAI accuracy, but better than the ERS offset accuracy. The synthetic Sentinel-1 images likely have a high signal-to-noise (SNR) ratio with respect to real Sentinel-1 data because they are simulated by only using the central part of the radar beam emitted by the ERS-2 SAR sensor. Therefore, the synthetic Sentinel-1 MAI interferogram could have a high coherence as well as low phase noise. For this reason, the $0.5 \%$ accuracy of the azimuth resolution has been achieved by the synthetic Sentinel-1 MAI measurement. However, an accuracy of about $20 \mathrm{~cm}$ is expected if the phase noise of real Sentinel-1 data is similar to that of ERS data, and the achievable accuracy could be about $16 \mathrm{~cm}$ if the phase noise of real Sentinel-1 data is close to that of ALOS PALSAR data [14]. Based on (4) and our analysis in this study, we can see that the accuracy of along-track displacements achieved by the MAI measurement largely depends on the phase noise of the Sentinel-1 data. Due to a much shorter repeat of Sentinel-1, we expect much higher coherence from Sentinel-1 than ERS and Envisat images. Consequently, we could measure the along-track displacements by the Sentinel-1 MAI method with an accuracy of less than $20 \mathrm{~cm}$ if the Sentinel-1 sensor has lower radar noise.

The comparison between the synthetic Sentinel-1 offset displacements with GPS measurements is shown in Fig. 4(d). The rms error is $27.5 \mathrm{~cm}$. This is 2.8 times worse than the Sentinel1 MAI method and is about twice as good as the expected accuracy of $48-60 \mathrm{~cm}$, which corresponds to $2.4 \%-3.0 \%$ of $20 \mathrm{~m}$ of the Sentinel-1's azimuth resolution, because the synthetic Sentinel-1 data have a high SNR. This result corresponds to $1.4 \%$ of the azimuth resolution, which is similar to the offset result of $1.6 \%$ achieved by the ALOS PALSAR [14]. The achievable accuracy might be around $48 \mathrm{~cm}$ if the $2.4 \%$ of the azimuth resolution estimated from ERS offset method is considered. Consequently, it could be difficult to effectively measure the along-track displacements by the offset tracking method from Sentinel-1 IW imagery.

\section{CONCLUSION}

We have tested the feasibility of along-track displacement measurement from Sentinel-1 IW mode SAR imagery, by simulating Sentinel-1 SAR images from an ERS InSAR pair bracketing the 1999 Hector Mine coseismic deformation and by generating along-track displacement maps from MAI and offset tracking techniques. The rms error between the alongtrack displacements from synthetic Sentinel-1 MAI and GPS measurements is about $9.6 \mathrm{~cm}$ or only $0.5 \%$ of the azimuth resolution. This accuracy is slightly better than ERS offset tracking method and about three times better than Sentinel-1 offset tracking technique. We recommend that the MAI method will be useful for mapping along-track displacements due to 
earthquakes and volcanic activities from the background operation mode of Sentinel-1 IW imagery.

\section{ACKNOWLEDGMENT}

The authors would like to thank three anonymous reviewers for the critical reviews and constructive comments.

\section{REFERENCES}

[1] F. Rostan, S. Riegger, W. Pitz, A. Torre, and R. Torres, "The C-SAR instrument for the GMES Sentinel-1 mission," in Proc. IGARSS, Jul. 2007, pp. 215-218.

[2] E. Attema, Mission requirements document for the European radar observatory Sentinel-1, Jul. 2005. [Online]. Available: http://esamultimedia. esa.int/docs/GMES/GMES_SENT1_MRD_1-4_approved_version.pdf

[3] P. Snoeij, E. Attema, M. Davidson, N. Floury, G. Levrini, B. Rosich, and B. Rommen, "Sentinel-1, the GMES radar mission," in Proc. IEEE Radar Conf., May 2008, pp. 1-5.

[4] J. H. Dieterich and R. W. Decker, "Finite element modeling of surface deformation associated with volcanism," J. Geophys. Res., vol. 80, no. 29, pp. 4094-4102, Oct. 1975.

[5] T. J. Wright, B. E. Parsons, and Z. Lu, "Toward mapping surface deformation in three dimensions using InSAR," Geophys. Res. Lett., vol. 31, no. 1, pp. L01 607-1-L01 607-5, Jan. 2004. doi:10.1029/2003GL018827.

[6] R. Michel, J. P. Avouac, and J. Taboury, "Measuring ground displacements from SAR amplitude images: Application to the Landers earthquake," Geophys. Res. Lett., vol. 26, no. 7, pp. 875-878, 1999.

[7] T. Strozzi, A. Luckman, T. Murray, U. Wegmuller, and C. L. Werner, "Glacier motion estimation using SAR offset-tracking procedures," IEEE Trans. Geosci. Remote Sens., vol. 40, no. 11, pp. 2384-2391, Nov. 2002.

[8] F. Casu, A. Manconi, A. Pepe, and R. Lanari, "Deformation timeseries generation in areas characterized by large displacement dynamics: The SAR amplitude pixel-offset SBAS technique," IEEE Trans. Geosci. Remote Sens., vol. 49, no. 7, pp. 2752-2763, Jul. 2011.

[9] N. B. D. Bechor and H. A. Zebker, "Measuring two-dimensional movements using a single InSAR pair," Geophys. Res. Lett., vol. 33, no. 16, pp. L1611-1-L16311-5, Aug. 2006. doi:10.1029/2006GL026883.

[10] H.-S. Jung, J.-S. Won, and S.-W. Kim, "An improvement of the performance of multiple aperture SAR interferometry (MAI)," IEEE Trans. Geosci. Remote Sens., vol. 47, no. 8, pp. 2859-2869, Aug. 2009.

[11] S. Jonsson, H. Zebker, P. Segall, and F. Amelung, "Fault slip distribution of the $M_{w} 7.1$ Hector Mine, California, earthquake, estimated from satellite radar and GPS measurements," Bull. Seismol. Soc. Amer., vol. 92, no. 4, pp. 1377-1389, Apr. 2002.

[12] Y. Fialko, "Probing the mechanical properties of seismically active crust with space geodesy: Study of the coseismic deformation due to the $1992 M_{w} 7.3$ Landers (Southern California) earthquake," J. Geophys. Res., vol. 109, no. B3, pp. B03307-1-B03307-13, 2004. doi:10.1029/2003JB002756.

[13] Y. Fialko, M. Simons, and D. Agnew, "The complete (3-D) surface displacement field in the epicentral area of the 1999 Mw 7.1 Hector Mine earthquake, California, from space geodetic observations," Geophys. Res. Lett., vol. 28, no. 16, pp. 3063-3066, 2001.

[14] D. Sandwell, D. Myer, R. Mellors, M. Shimada, B. Brooks, and J. Foster, "Accuracy and resolution of ALOS interferometry: Vector deformation maps of the Father's Day intrusion at Kilauea," IEEE Trans. Geosci. Remote Sens., vol. 46, no. 11, pp. 3524-3534, Nov. 2008.

[15] H. S. Jung, Z. Lu, J. S. Won, M. P. Poland, and A. Miklius, "Mapping three-dimensional surface deformation by combining multiple-aperture interferometry and conventional interferometry: Application to the June 2007 eruption of Kilauea volcano, Hawaii," IEEE Geosci. Remote Sens. Lett., vol. 8, no. 1, pp. 34-38, Jan. 2011.

[16] G. Eigen and Y. Rasen, "Efficient full aperture processing of TOPS mode data using the moving band chirp $Z$-transform," IEEE Trans. Geosci. Remote Sens., vol. 49, no. 10, pp. 3688-3693, Oct. 2011.

[17] P. Prats, R. Scheiber, J. Mittermayer, A. Meta, and A. Moreira, "Processing of sliding spotlight and TOPS SAR data using baseband azimuth scaling," IEEE Trans. Geosci. Remote Sens., vol. 48, no. 2, pp. 770-780, Feb. 2010.

[18] R. M. Goldstein and C. L. Werner, "Radar interferogram filtering for geophysical applications," Geophys. Res. Lett., vol. 25, no. 21, pp. 40354038, Nov. 1998.
[19] H. A. Zebker and J. Villasenor, "Decorrelation in interferometric radar echoes," IEEE Trans. Geosci. Remote Sens., vol. 30, no. 5, pp. 950-959, Sep. 1992.

[20] D. C. Agnew, S. Owen, Z.-K. Shen, G. Anderson, J. Svarc, H. Johnson, K. E. Austin, and R. Reilinger, "Coseismic displacements from the Hector Mine, California, earthquake: Results from survey-mode global positioning system measurements," Bull. Seismol. Soc. Amer, vol. 92, no. 4, pp. 1355-1364, May 2002.

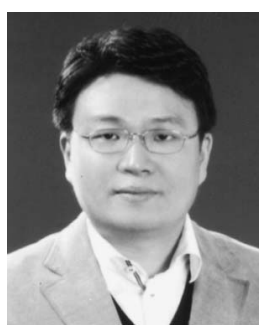

Hyung-Sup Jung (M'09) received the M.S. and Ph.D. degrees in geophysics and remote sensing from Yonsei University, Seoul, Korea, in 1998 and 2007, respectively.

$\mathrm{He}$ is currently an Assistant Professor with the Department of Geoinfomatics, The University of Seoul, Seoul. His primary research interests include developments of synthetic aperture radar (SAR), interferometric SAR (InSAR), multiple-aperture InSAR (MAI) and small baseline subset (SBAS) InSAR processors, and algorithms related to 3-D deformation mapping by combining MAI and InSAR and 2-D surface velocity estimation by combining MAI and along-track interferometry.

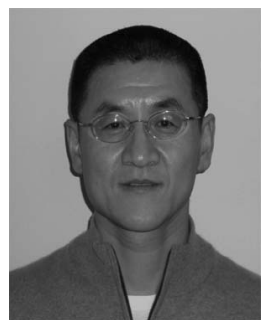

Zhong Lu (S'96-A'97-M'97-SM'07) received the M.S. degree from Peking University, Beijing, China, in 1992 and the Ph.D. degree from the University of Alaska Fairbanks, Fairbanks, in 1996.

$\mathrm{He}$ is a Physical Scientist with Cascades Volcano Observatory, United States Geological Survey (USGS), Vancouver, WA. He is a Principal Investigator of projects funded by the National Aeronautics and Space Administration (NASA), European Space Agency, Japan Aerospace Exploration Agency, German Space Agency, and USGS on the study of land surface deformation using satellite interferometric synthetic aperture radar (SAR) (InSAR) imagery. His research interests include technique developments of SAR, InSAR, and persistent scatterer InSAR processing and their applications on natural hazard monitoring and natural resource management. He has produced more than 40 lead-authored and 60 coauthored peer-reviewed journal articles and book chapters focused on InSAR techniques and applications.

Dr. Lu was the recipient of an American Society for Photogrammetry and Remote Sensing Award for Best Scientific Paper in Remote Sensing, NASA Group Achievement Award, NASA Certificate of Appreciation, Raytheon Distinguished Level Award for Excellence in Technology, Science Applications International Corporation Technical Fellow, and Jerald Cook Memorial Award. $\mathrm{He}$ is a committee member of the International User Team for Radarsat-C SAR Constellations, the GeoEarthscope InSAR User Working Group, the NASA's Alaska Satellite Facility User Working Group, and NASA deformation, ecosystem structure, and dynamics of ice-radar Science Definition Team.

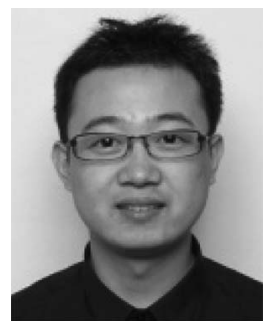

Lei Zhang (S'08-M'11) was born in Yantai, China, in 1981. He received the M.Sc. degree in geodesy and geodynamics from Tongji University, Shanghai, China, in 2007, with a thesis on fault slip inversion using interferometric synthetic aperture radar (SAR) and GPS data based on a triangular dislocation model.

He is currently a Research Associate with the Department of Land Surveying and Geo-Informatics, The Hong Kong Polytechnic University, Kowloon, Hong Kong. His research interests focus on developing advanced processing techniques for multiple SAR images and the application of multitemporal interferometric analysis to the retrieval of geophysical parameters and displacement monitoring, with emphasis on natural hazards. 